\title{
Using novobiocin as a specific inhibitor of breast cancer resistant protein to assess the role of transporter in the absorption and disposition of topotecan
}

\author{
Yaming Su, Peidi Hu, Sung-Hack Lee, Patrick J. Sinko \\ Department of Pharmaceutics (YS, PH, SHL and PJS), Ernest Mario School of Pharmacy Rutgers, The State \\ University of New Jersey, 160 Frelinghuysen Road, Piscataway, New Jersey 08854, USA
}

Received August 5, 2007; Revised September 24, 2007; Accepted October 19, 2007; Published October 22, 2007

\begin{abstract}
Purpose. To investigate the role of intestinal breast cancer resistant protein (BCRP) in the absorption and disposition of topotecan (TPT) using novobiocin (NOV) as a specific inhibitor. Methods. Transporter inhibition specificity of NOV was assessed in cells overexpressing BCRP or Pgp. SpragueDawley rats were orally or intravenously dosed with TPT (2 and $1 \mathrm{mg} / \mathrm{kg}$ for p.o. and i.v., respectively) with or without oral coadministration of NOV $(50 \mathrm{mg} / \mathrm{kg})$. Pharmacokinetic parameters of TPT were obtained by noncompartmental analysis. To assess the role of Bcrp in TPT intestinal permeation, rat ileal segment was perfused with $10 \mu \mathrm{M}$ TPT in the presence or absence of NOV $(500 \mu \mathrm{M})$, TPT permeability was calculated based on drug appearance in mesenteric blood. To assess the role of Bcrp in TPT intestinal secretion, rat ileal segment was perfused with saline in the presence or absence of NOV $(500 \mu \mathrm{M})$, while TPT was i.v. infused into rat. Intestinal secretion of TPT was calculated based on drug appearance in the perfusate. Results. NOV significantly inhibited efflux activity of Bcrp, but not Pgp. Coadministration of NOV markedly increased oral TPT $\mathrm{AUC}_{0-720}$ and $\mathrm{C}_{\max }$ by 3 - and 4.5-fold, respectively, and decreased systemic clearance of i.v. injected TPT (from $44.40 \pm 7.28$ without NOV to $29.44 \pm 1.99 \mathrm{ml} / \mathrm{min} / \mathrm{kg}$ with NOV). The inclusion of NOV in perfusate significantly increased TPT apparent permeability (intestinal mucosal-to-serosal) from $0.81 \pm$
\end{abstract}

$0.30 \times 10^{-6}$ to $1.26 \pm 0.12 \times 10^{-6} \mathrm{~cm} / \mathrm{s}$, while, the intestinal secretion of TPT was reduced by $\sim 50 \%$ when NOV was included in perfusate. Conclusions. The present study establishes in vitro and in vivo inhibition potency and specificity of NOV on BCRP and provides direct evidence that intestinal Bcrp plays an important role in limiting the oral absorption and influencing the systemic elimination of TPT.

\section{INTRODUCTION}

It is well documented that some intestinal transporters play an important role in drug permeation across the brush border membrane [1]. The absorptive transporters (e.g., PepT1) facilitate the drug transport from the intestinal lumen into the blood circulation, consequently enhancing oral drug exposure [2], while secretory transporters (e.g., Pgp) significantly restrict the oral absorption of certain drugs by actively extruding the compounds from the serosal to mucosal side of the intestinal membrane [3]. BCRP is a member of the ATP-binding cassette (ABC) transporter family. It was originally identified from drug resistant cancer cells $[4,5]$.

\footnotetext{
Corresponding Author: Patrick J. Sinko, PhD, RPh, Parke-Davis Professor of Pharmaceutics and Drug Delivery Chair, Department of Pharmaceutics, Ernest Mario School of Pharmacy Rutgers, The State University of New Jersey, 160 Frelinghuysen Road, Piscataway, New Jersey, Email: sinko@rci.rutgers.edu
} 
A subsequent study [6] demonstrated that BCRP is also highly expressed at organs or tissues (e.g., intestine, liver, kidney, BloodBrain-Barrier and placenta) important for the absorption and disposition of drugs such as TPT.

Oral TPT administration has been enthusiastically pursued in recent years since it was found that oral regimens led to similar therapeutic outcomes as i.v. injection, oral administration is desirable since patients could then be treated on an outpatient basis, and patients tolerated oral TPT well $[7,8]$. However, the oral bioavailability of TPT is low and variable [9] and it is still only available as an i.v. injection for use in humans. Jonker et al. compared TPT exposure in Bcrp knockout mice, and found that the AUC of orally administered TPT is about 6-fold higher in Bcrp deficient mice than in wild-type mice [10]. Chemically knocking down murine Bcrp function using a potent BCRP/Pgp inhibitor, GF120918, also resulted in a significant increase in TPT oral absorption [11]. Further studies of TPT in combination with GF120918 demonstrated enhanced oral bioavailability in the clinical setting [12]. However, to our knowledge, no studies have been carried out to directly assess the role of intestinal BCRP on the absorption and disposition of TPT.

The recognition of the importance of BCRP in pharmacokinetics and therapeutic effectiveness of anti-cancer drugs led to an intense search for BCRP inhibitors [12-16]. Recent in vitro studies demonstrated that NOV, a coumermycin antibiotic, significantly sensitizes BCRP-overexpressed cancer cells to TPT or mitoxantrone (MX), suggesting that it is a potent BCRP inhibitor [17-19]. However, to the best of our knowledge, no studies have been carried out to asses the specificity of BCRP inhibition by NOV (e.g., the effect of NOV on Pgp-mediated transport), and it remains unclear whether NOV can modulate BCRP-mediated drug transport in vivo.

Therefore, the objectives of the current study were to i) investigate the BCRP inhibition specificity and potency of NOV and ii) directly assess the role of intestinal BCRP in the absorption and disposition of TPT using intestinal perfusion approach.

\section{MATERIALS AND METHODS}

\section{Materials.}

NOV, doxorubicin (DOX), Rh123 and polyD-lysine was purchased from Sigma Chemical (St. Louis, MO). MTT [3-(4,5dimethylthiazol-2-yl)-2,5-diphenyl

tetrazolium] was purchased from Acros Organics (Morris Plains, NJ). FTC (Fumitremorgin C) was purchased from AXXORA, LLC (San Diego, CA). TPT and GF1120918 were provided by GlaxoSmithKline, Inc. (Research Triangle Park, NC).

\section{Cell lines and animal.}

HEK (human embryonic kidney) cells transfected with empty plasmid (pcDNA3, HEK-Mock) or BCRP gene (HEK-BCRP) were provided by Dr. Eric Rubin (Cancer Institute of New Jersey) who originally received them from Dr. Susan Bates (National Cancer Institute). Transfected HEK cells were cultured in MEM medium supplemented with $10 \%$ fetal bovine serum (FBS) and $300 \mu \mathrm{g} / \mathrm{mL}$ G418. MDCK (Mardin-Darby canine kidney) wild type (MDCK-wt) and stable transfectant MDCK cells overexpressing human Pgp (MDCKMDR1) were obtained from NIH, and were cultured in Dulbecco's Modified Eagle's Medium (DMEM, with high glucose and glutamine) supplemented with 10\% FBS, $1 \%$ nonessential amino acids, $100 \mathrm{U} / \mathrm{mL}$ penicillin and $100 \mu \mathrm{g} / \mathrm{mL}$ streptomycin. All the essential cell culture materials (FBS, MEM, DMEM, and G418) were purchased from Invitrogen (Carlsbad, CA). The cells are maintained at $37{ }^{\circ} \mathrm{C}$ in a humidified incubator supplied with $5 \%$ CO2 in air. Jugular vein cannulated male Sprague-Dawley (SD) rats were purchased from Hilltop Lab Animals, 
Inc. (Scottdale, PA). The IACUC (Institutional Animal Care and Use Committee) of Rutgers University approved the animal experiment protocols in this study.

\section{Cell growth inhibition assay.}

Antiproliferative effects of drugs on MDCK and MDCK-MDR1 cells growth were determined using a MTT assay as described previously [20]. IC $_{50}$ values (concentrations associated with $50 \%$ inhibition of growth) of DOX in the presence or absence of $30 \mu \mathrm{M}$ of NOV were obtained by curve-fitting analysis of the percentage of control (untreated cells) absorbance at $570 \mathrm{~nm}$ versus drug concentrations, using Prism (Version 4; GraphPad Software, Inc.). The data were fitted to a sigmoidal inhibitory effect model governed by the following equation:

$$
Y=100 \% /\left(1+\left(X / I C_{50}\right)^{S}\right)
$$

where $Y$ was the percentage of control absorbance at $570 \mathrm{nM}$ from untreated cells, $X$ was the drug concentration, $S$ is the slope factor. Student's t-test was performed using Sigma Stat (Version 2.03; SPSS Inc., Chicago, IL) to compare the difference of $\mathrm{IC}_{50}$ value with $p<0.05$ considered as statistically significant.

\section{Cellular drug accumulation.}

HEK-Mock or HEK-BCRP cells were subcultured by trypsinization with $0.05 \%$ trypsin-EDTA and plated onto 24-well plates at a density of $2 \times 10^{5}$ cells $/ \mathrm{cm}^{2}$. The cell culture vessel was pre-coated with poly-Dlysine to enhance the cell binding to wells. Uptake of TPT was studied 1 day after confluence. The cells were prewashed in $3 \times$ $0.5 \mathrm{ml}$ of uptake medium (Hank's balanced salt solution, HBSS containing $8 \mathrm{~g} / \mathrm{L} \mathrm{NaCl}$, $0.05 \mathrm{~g} / \mathrm{L} \mathrm{Na}_{2} \mathrm{HPO}_{4}, 0.4 \mathrm{~g} / \mathrm{L} \mathrm{KCl}, 0.06 \mathrm{~g} / \mathrm{L}$ $\mathrm{KH}_{2} \mathrm{PO}_{4}, 0.098 \mathrm{~g} / \mathrm{L} \mathrm{MgSO}_{4}, 0.14 \mathrm{~g} / \mathrm{L} \mathrm{CaCl}_{2}$, $1 \mathrm{~g} / \mathrm{L}$ D-glucose) and then incubated at $37{ }^{\circ} \mathrm{C}$ in $0.5 \mathrm{ml}$ of the same medium containing 10 $\mu \mathrm{M}$ TPT in the presence or absence of transporter inhibitors (i.e., $30 \mu \mathrm{M}$ of NOV or $10 \mu \mathrm{M}$ of FTC). The concentration of TPT (i.e., $10 \mu \mathrm{M}$ ) is chosen according to the previous literature report [11]. After the cells had been incubated for the indicated time period (30 or $60 \mathrm{~min}$ ), the uptake medium was immediately removed from the wells, and the cells were washed with $3 \times 0.5 \mathrm{~mL}$ of ice-cold uptake buffer. The trace amount of $0.05 \%$ trypsin-EDTA was used to detach the cells for subsequent cell counting, then 300 $\mu \mathrm{L}$ of perchloric acid (70\%) was added to the well to lyse the cells. The consequent sample preparation procedure for TPT quantitation using HPLC is described in section of “Analytical Methods". Student's t-test was performed using Sigma Stat (Version 2.03; SPSS Inc., Chicago, IL) to compare the difference of TPT uptake with $p<0.05$ considered as statistically significant.

MDCK-wt or MDCK-MDR1 cells were cultured on Lab-Tek $® I I$ Chamber Slide ${ }^{\mathrm{TM}}$ System (Nalge Nunc International Corp, Naperville, IL), and incubated with 10 $\mu \mathrm{M}$ of Rh123 (prepared in HBSS buffer) at $37{ }^{\circ} \mathrm{C}$ in the presence or absence of transporter inhibitors (i.e., $100 \mu \mathrm{M}$ NOV or 1 $\mu \mathrm{M}$ GF120918) for 2-h to achieve the steady state of drug accumulation, then the cells were washed in $3 \times 0.5 \mathrm{ml}$ ice-cold HBSS buffer. The cellular accumulation of Rh123 was visualized using fluorescence microscopy (Zeiss Axiostar Plus fluorescence microscope).

\section{Pharmacokinetics of orally administered TPT.}

Jugular vein cannulated male SpragueDawley rats (200-250 g) were maintained on a 12-h light/dark cycle at the Rutgers Animal Care Facility and acclimatized for at least 3 days before the study. The animals were fasted overnight (water ad libitum) the day before experiment. NOV was dissolved in normal saline containing $5 \%$ dextrose as 33.3 $\mathrm{mg} / \mathrm{ml}$, and then dosed orally by gavage (50 $\mathrm{mg} / \mathrm{kg}$ ) to three rats (i.e., Bcrp inhibition group), the same volume of vehicle (i.e., 
normal saline containing 5\% dextrose) was dosed to the other three rats as a control. Three to five minutes later, the animals were administered 2 or $1 \mathrm{mg} / \mathrm{kg}$ TPT $(0.8 \mathrm{mg} / \mathrm{ml}$ dissolved in saline containing 5\% dextrose) orally (by gavage) or i.v. (by tail vein injection), respectively. Blood samples (200$300 \mu \mathrm{l})$ were collected into heparinized tubes from the jugular vein cannula at the designated time point. When TPT was orally dosed, the blood was collected at 0 (before TPT administration), 5, 10, 30, 60, 120, 240, 480 and 720 min. When TPT was dosed by i.v. bolus, the blood sampling schedule was 0 (before TPT administration), 1, 5, 10, 30, 60, 120, 240 and 480. The plasma samples were obtained by centrifugation and stored at $80^{\circ} \mathrm{C}$ until drug analysis. During the experiment, the rats had free access to water at all times and free access to food (standard chow) beginning $6 \mathrm{~h}$ after $\quad$ TPT administration. The pharmacokinetic parameters of TPT were obtained by noncompartmental analysis using WinNonlin version 3.1 (Pharsight, Mountain View, CA). The AUC was calculated using the trapezoidal rule method. The statistical differences in the pharmacokinetic parameters of TPT between the control and NOV coadministered groups were tested using paired Wilcoxon signed rank test (two-sided). The level of significance was set at $p<0.05$.

\section{Single pass intestinal perfusion (SPIP) with mesenteric vein sampling.}

Male Sprague-Dawley rats (300-350 g) used in the intestinal perfusion experiments were fasted overnight (water ad libitum). Rats were anesthetized with a ketamine $(80 \mathrm{mg} / \mathrm{ml})$ and xylazine $(12 \mathrm{mg} / \mathrm{ml})$ solution at a dose of $0.1 \mathrm{ml} / \mathrm{kg}$ by intramuscular injection. Animals were placed on a $37^{\circ} \mathrm{C}$ heating pad during surgery and throughout the in situ intestinal perfusion. Donor blood was obtained from two to three animals per experiment (total of $35-40 \mathrm{ml}$ ) by cardiac puncture. Blood was diluted 5:1 with saline containing heparin (50 $\mathrm{U} / \mathrm{ml}$ ) before infusion.
The in situ intestinal perfusion with mesenteric sampling procedure is similar as described before [21]. Briefly, three procedures were performed: tail vein cannulation for infusion of donor blood, isolation of an ileal segment for drug perfusion, and cannulation of the mesenteric vein for continuous collection of blood. Immediately after implanting the tail vein cannula (Angiocath Shielded i.v. catheter, 24G, 0.75 in, $0.7 \times 19 \mathrm{~mm}$, BD Medical Systems, Sandy, Utah.), a interlink injection site (Baxter Healthcare Corp., Deerfield, IL) was installed at the end of catheter to provide an injection or infusion site. A heparin solution $(0.5 \mathrm{ml}$ of $200 \mathrm{U} / \mathrm{ml})$ was injected into tail vein cannula to make the rat blood heparinized. After the tail vein cannulation was performed, a 5-cm-long midline incision was made and the ileum was located by using the ileocecal junction as a point of reference. A 9- to 15-cm-long segment of ileum was chosen based on the pattern of the mesenteric venules that provide an optimal site for mesenteric cannulation. Incisions were made at both ends of the intestinal segment being careful to avoid cutting of the blood vessels. The segment was then gently flushed using pre-warmed saline. Intestinal cannulas (Tygon R-3603, ID: 1/8 in, OD: 3/16 in, Fisher Scientific, Pittsburgh, PA) were inserted at each end and ligated using silk suture (3-0 U.S.P.). The tissue surrounding the mesenteric vein to be cannulated was gently removed with forceps. Blank perfusion buffer (1× PBS) or buffer containing $500 \mu \mathrm{M}$ NOV (for inhibition studies) was infused into the intestinal segment during this time at a rate of $0.2 \mathrm{ml} / \mathrm{min}$ from a syringe pump (Harvard Apparatus) to test the free flow of solution across the segment. Mesenteric cannulation was performed using the Angiocath $24 \mathrm{G}$ catheter $(0.75 \mathrm{in}, 0.7 \times 19 \mathrm{~mm}$, BD Medical Systems, Sandy, Utah) in which the top 1-cm beveled tip was cut so that this 1 -cm tip remained in the mesenteric vein after the needle was withdrawn. The cannula was then secured in place using Cyanoacrylate glue. It is critical that the integrity of 
mesenteric artery (in parallel to mesenteric vein) is not comprised at the site of cannulation. The cannula was then connected to a 50-cm-long piece of polyethylene-50 (BD Biosciences) tubing that allowed blood to flow into vials placed approximately $5 \mathrm{~cm}$ below the plane of the animal. Donor blood was infused through the tail vein using a syringe pump (Harvard Apparatus) and the rate was adjusted based on the outflow from the mesenteric blood $(\sim 0.4 \mathrm{ml} / \mathrm{min})$. At the end of the study, the length of intestinal segment was measured from the end of the inlet cannula to the beginning of the exit cannula. Animals were sacrificed by overdosing with phenobarbital.

The perfusion buffer was phosphate buffered saline (i.e., $1 \times$ PBS having $3 \mathrm{mM}$ $\mathrm{Na}_{2} \mathrm{HPO}_{4}, 1 \mathrm{mM} \mathrm{KH} \mathrm{KH}_{4}, 155 \mathrm{mM} \mathrm{NaCl}$ ) with $\mathrm{pH}$ adjusted to 7.0. TPT was dissolved in perfusion buffer at concentration of $10 \mu \mathrm{M}$ in the absence or presence of $500 \mu \mathrm{M}$ of NOV. The final osmolality and $\mathrm{pH}$ of the perfusates were $300-310 \mathrm{mOsm} / \mathrm{kg}$ and 6.97.1, respectively.

Once the intestinal perfusion was initiated by infusing drug solution at 0.2 $\mathrm{ml} / \mathrm{min}$, blood from the mesenteric vein was continuously collected into pre-weighed 2-ml centrifugation tubes up to 100 -min (5-min interval). The sample tubes were then reweighed to obtain the mass of collected blood. Subsequently, volume of blood samples was determined gravimetrically assuming specific density of blood as 1.0 $\mathrm{mg} / \mathrm{ml}$. The collected blood were centrifuged at 16, $000 \mathrm{~g}$ for 8-min, and the obtained plasma was immediately frozen and stored at $-80{ }^{\circ} \mathrm{C}$ until analysis.

The permeability of TPT across rat intestine was calculated based on the drug appearance in the blood using the following equation [21].

$$
P_{\text {blood }}=J_{s s}(2 \pi r l \cdot C)
$$

where $r$ is the radius of the intestinal lumen, $l$ is the length of the segment $(\mathrm{cm}), C$ is the logarithmic mean concentration of TPT in the intestinal lumen. $J_{s s}$ is the steady-state flux of TPT appearing in mesenteric blood, which can be obtained from the following empirical first-order equation.

$$
J=J_{s s} \cdot\left[1-e^{-k(t-t l a g)}\right]
$$

where $J$ is the flux at time $t . t_{\text {lag }}$ is the apparent lag time to fill the intestinal segment with drug solution and establish the steady state concentration gradients along the segment and across the intestinal membrane. $J$ was experimentally determined using the following equation.

$$
J=\Delta M_{B} / \Delta t
$$

where $\Delta M_{B}$ is the mass of TPT in the mesenteric blood collected within 5-min (i.e., $\Delta t)$.

\section{Intestinal exsorption (secretion) of TPT.}

Jugular vein cannulated male SpragueDawley rats were fasted overnight and anesthetized with ketamine $(80 \mathrm{mg} / \mathrm{ml})$ and xylazine $(12 \mathrm{mg} / \mathrm{ml})$ solution at a dose of $0.1 \mathrm{ml} / \mathrm{kg}$ by intramuscular injection. The rats were affixed on a heating pad in a supine position and kept at $37^{\circ} \mathrm{C}$ to maintain body temperature. A Angiocath 24G catheter was used for the tail vein cannulation so that drug solutions could be administered. The cannulated jugular vein was used for blood sampling. Lactated Ringer's Injection (Hospira, INC., Lake Forest, IL) with 5\% dextrose was infused via tail vein cannulation as a stabilization period of about $30 \mathrm{~min}$ at a rate of $2 \mathrm{ml} / \mathrm{h} / \mathrm{rat}$. During the stabilization period, a 5-cm-long midline incision was made and a $10-\mathrm{cm}$ long ileum was located by using the ileocecal junction as a point of reference. The lumen of the ileum was flushed with $20 \mathrm{ml}$ of saline pre-warmed at 37 ${ }^{\circ} \mathrm{C}$. The proximal end of the lumen was catheterized with an in-flow silicone cannula (Tygon R-3603, ID: 1/8 in, OD: 3/16 in, Fisher Scientific Company, Pittsburgh, PA), which was connected to a syringe pump 
(Harvard Apparatus). The distal end of ileum was also catheterized with an out-flow silicone cannula, and intestinal effluents were periodically collected to the pre-weighted tube. Volume of effluent was determined gravimetrically assuming specific density of effluent as $1.0 \mathrm{mg} / \mathrm{ml}$. The experimental setup is illustrated in Figure 1.

In the current study, TPT exsorption were assessed when plasma concentration at steady state was $100 \mathrm{ng} / \mathrm{ml}$ after i.v. infusion. Infusion rate was calculated using following equation:

$$
K_{0}=C_{s s} \times C L
$$

where $K_{0}$ is infusion rate, $C_{s s}$ is desired plasma concentration at steady state (i.e., 100 $\mathrm{ng} / \mathrm{ml})$. $C L$ is total clearance, which was estimated from previous TPT i.v. bolus injection data using Noncompartmental model (i.e., $44.4 \mathrm{ml} / \mathrm{min} / \mathrm{kg}$ ). Thus, the calculated infusion rate (mass-wise) was 4440 $\mathrm{ng} / \mathrm{min} / \mathrm{kg}$. According to the previous experiment [22], infusion rate (volume-wise) for rat was $2 \mathrm{ml} / \mathrm{h} / \mathrm{rat}$, or $0.16 \mathrm{ml} / \mathrm{min} / \mathrm{kg}$ assuming body weight of rat is $200 \mathrm{~g}$. Therefore, TPT solution for i.v. infusion was prepared as $0.028 \mathrm{mg} / \mathrm{ml}$ in Lactated Ringer's injection containing $5 \%$ dextrose.

To quickly achieve the desired plasma concentration, a loading dose of TPT was administered as i.v. bolus injection. The loading dose was calculated according to the following equation:

$$
X_{0}=C_{s s} \times V
$$

where $X_{0}$ is loading dose, $C_{s s}$ is desired TPT plasma concentration at steady state, $V$ is apparent volume of distribution, which was estimated from previous TPT i.v. bolus injection data using Noncompartmental model (i.e., $4157 \mathrm{ml} / \mathrm{kg}$ ). Thus, the calculated loading dose was $0.42 \mathrm{mg} / \mathrm{kg}$, or $0.525 \mathrm{ml} / \mathrm{kg}$ of $0.8 \mathrm{mg} / \mathrm{ml}$ TPT prepared in Lactated Ringer's injection containing 5\% dextrose.

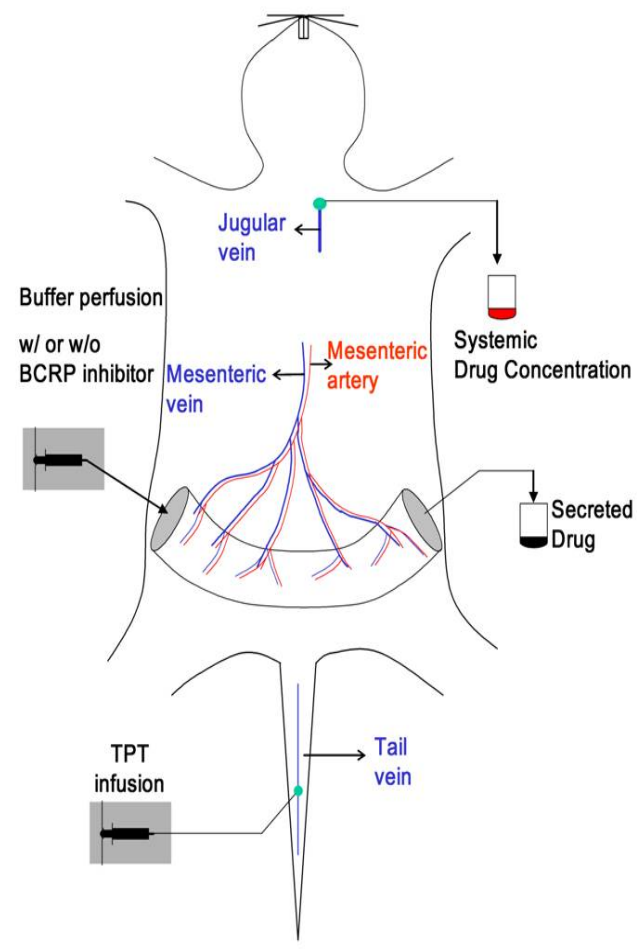

Figure 1. Schematic representation of intestinal exsorption (secretion) of TPT. 
TPT was dissolved at a concentration of 0.8 or $0.028 \mathrm{mg} / \mathrm{ml}$ in Lactated Ringer's Injection containing $5 \%$ dextrose. After the stabilization period, TPT solution $(0.8 \mathrm{mg} / \mathrm{ml})$ was injected i.v. as a bolus with dose of 0.42 $\mathrm{mg} / \mathrm{kg}$, followed by a constant infusion of TPT solution $(0.028 \mathrm{mg} / \mathrm{ml})$ via tail vein cannula at a rate of $4440 \mathrm{ng} / \mathrm{min} / \mathrm{kg}$ to attain a steady-state plasma concentration of TPT at approximately $100 \mathrm{ng} / \mathrm{ml}$. At this time point, the single perfusion of normal saline into the ileal lumen was also started at a rate of $0.2 \mathrm{ml} / \mathrm{min}$. After a steady-state plasma TPT concentration was achieved (approximately 50 min after the initiation of TPT infusion), the intestinal effluent and blood were collected every $10 \mathrm{~min}$ for $40 \mathrm{~min}$ as a control phase. Then, the perfusate was changed to the normal saline in the absence (sham inhibition) or presence of $500 \mu \mathrm{M}$ of NOV (BCRP inhibition). After $40 \mathrm{~min}$ of perfusion for stabilization, the intestinal effluent and blood were further collected periodically for an additional $40 \mathrm{~min}$ as an inhibition phase. The volume of blood or intestinal perfusate samples was determined gravimetrically assuming specific density of blood or perfusate as $1.0 \mathrm{mg} / \mathrm{ml}$. TPT concentration in plasma or perfusate was analyzed using HPLC. The exsorption of TPT from blood to ileal lumen was expressed as an exsorption clearance $\left(C L_{\text {intestine }}, \mathrm{ml} / \mathrm{min} / 15 \mathrm{~cm}\right.$ ileum) calculated using the following equation.

$$
C L_{\text {intestine }}=\left(\Delta M_{L} / \Delta t\right) / C_{\text {blood }}
$$

where $\Delta M_{L}$ is the mass of TPT in the intestinal effluent collected within $10 \mathrm{~min}$ (i.e., $\Delta t$ ). $C_{\text {blood }}$ is the TPT concentration in blood sample withdrawn at the intermediate time point of each intestinal effluent collection. At the end of the study, the length of intestinal segment was measured from the end of the inlet cannula to the beginning of the exit cannula. Animals were sacrificed by overdosing with phenobarbital.

Repeated-Measures Analysis using SAS (SAS Institute Inc, Cary, NC) were performed to assess the change of TPT intestinal exsorption when BCRP is inhibited. Briefly, TPT exsorption clearance in control or inhibition phase was averaged, then the change of the averaged TPT exsorption clearance that is potentially introduced by the treatment (i.e., sham or BCRP inhibition) was compared between different treatments. $p<0.05$ was regarded as statistical significance.

\section{Analytical methods (high performance liquid chromatography, HPLC).}

To measure the intracellular accumulation of TPT, $300 \mu \mathrm{L}$ of perchloric acid (70\%) was added to $10^{6}$ HEK-Mock or HEK-BCRP cells, and shaken for $10 \mathrm{~min}$. Afterwards, 50 $\mu \mathrm{L}$ of acetonitrile and $0.1 \mathrm{M} \mathrm{HCl}$ mixture (80:20) was added to the sample and the mixture was shaken and sonicated for another $10 \mathrm{~min}$. Proteins were then precipitated by centrifugation for 10-min at $16,000 \mathrm{~g} .100 \mu \mathrm{L}$ of the resulting supernatant, was injected into the HPLC system for TPT analysis. To measure the plasma or perfusate TPT concentration, $100 \mu \mathrm{l}$ of plasma or perfusate was added to $200 \mu \mathrm{l}$ of perchloric acid (70\%), and shaken for $10 \mathrm{~min}$. Afterwards, $50 \mu \mathrm{L}$ of acetonitrile and $0.1 \mathrm{M} \mathrm{HCl}$ mixture $(80: 20)$ was added to the sample and the mixture was shaken and sonicated for another 10-min. Proteins were then precipitated by centrifugation for $10 \mathrm{~min}$ at $16,000 \mathrm{~g}$. Of the resulting supernatant, $100 \mu \mathrm{L}$ was injected into HPLC system for TPT analysis.

The HPLC setup consisted of Waters 600 pump (Waters, Milford, MA), Waters 717plus Autosampler and Shimadzu RF510 spectrofluorometer (Shimadzu, Kyoto, Japan) with excitation at $359 \mathrm{~nm}$ and emission at 536 nm. The Millennium 32 software (Waters, Milford, MA) was used for data acquisition and processing. Separations were achieved with Zorbax Eclipse XDB column (C8, $4.6 \times$ 150 mm, $5 \mu \mathrm{m}$; Agilent, Palo Alto, CA). The mobile phase consisted of water with $0.1 \%$ trifluoroacetic acid (A) and acetonitrile (B). Gradient of B, 10\% (0 min)-10\% (2 min)$50 \%$ (7 min)-50\% (7.5 min)-10\% (8 min). 
The pump flow rate was $1 \mathrm{~mL} / \mathrm{min}$. Retention time of TPT under the current analytical condition is $8.8 \mathrm{~min}$. The acidic environment during sample preparation and separation in HPLC converts the ring-opened TPT into lactone form, so TPT concentration analyzed under the present condition is the sum of lactone and hydroxyl acid forms of TPT. The lowest detection limit is $1 \mathrm{ng} / \mathrm{ml}$ with the linear range of $1-500 \mathrm{ng} / \mathrm{ml}$. Intra-day precision and accuracy was determined by analyzing quality control standards (rat plasmas spiked with TPT at 10, 100 and 500 $\mathrm{ng} / \mathrm{ml}$ ) five times a day randomly, inter-day precision and accuracy was determined from the analysis of each quality control standards (10, 100 and $500 \mathrm{ng} / \mathrm{ml}$ ) once on five consecutive days. The intra- and inter-day accuracy ranged from 98.2 to 105.6 and 95.6 to $102.9 \%$, respectively. The intra- and interday assay precision (CV\%) ranged from 0.40 to 2.40 and 4.49 to 4.52 , respectively.

The plasma sample preparation for HPLC analysis of NOV is different from TPT. Briefly, $400 \mu$ l of ice cold methanol were added to $100 \mu$ l of plasma, and then sonicated for $10 \mathrm{~min}$. The mixture was centrifuged at $2000 \mathrm{~g}$ for $10 \mathrm{~min}$, and $100 \mu \mathrm{l}$ of supernatant was injected into HPLC system for analysis. HPLC consisted of Waters 600 pump (Waters, Milford, MA), Waters 717plus Autosampler and Waters 486 UV-detector with absorbance at $254 \mathrm{~nm}$. The Millennium 32 software (Waters, Milford, MA) was used for data acquisition and processing. Separations were achieved with Nova-Pak ${ }^{\circledR}$ column $(\mathrm{C} 18,3.9 \times 150 \mathrm{~mm}$; Waters, Milford, MA). The mobile phase consisted of water with $0.1 \%$ trifluoroacetic acid (A) and acetonitrile (B). Gradient of B: 0\% (0 min)-80\% (9 min)-0\% (10 min)-50\% (7.5 min)-10\% (8 min). The pump flow rate was $1 \mathrm{~mL} / \mathrm{min}$. Retention time of NOV under the current analytical condition is $13.1 \mathrm{~min}$. The lowest detection limit is $1 \mu \mathrm{M}$ with the linear range of 1-500 $\mu \mathrm{M}$. Intra-day precision and accuracy was determined by analyzing quality control standards (rat plasmas spiked with NOV at 10, 100 and $500 \mu \mathrm{M}$ ) five times a day randomly, inter-day precision and accuracy was determined from the analysis of each quality control standards (10, 100 and $500 \mu \mathrm{M}$ ) once on five consecutive days. The intra- and inter-day accuracy ranged from 97.5 to 107.6 and 98.6 to $108.7 \%$, respectively. The intra- and inter-day assay precision (CV\%) ranged from 0.52 to 2.35 and 0.83 to 2.01 , respectively.

\section{RESULTS}

\section{Inhibition specificity of NOV.}

The current results showed that $30 \mu \mathrm{M}$ NOV significantly inhibited BCRP-mediated TPT efflux (Figure 2), indicating that it is a potent BCRP inhibitor consistent with a previous report [17]. Since the substrate/inhibitor spectrum of BCRP often overlaps with Pgp $[23,24]$, the inhibitory specificity of NOV was also investigated. As shown in Figure $3 \mathrm{~A}, \mathrm{IC}_{50}$ value of DOX in Pgp-transfected MDCK cells (MDCK-MDR1) were approximately 6.8-fold higher than that in wild type cells (MDCK-wt). GF120918 (1 $\mu \mathrm{M}$ ), a potent Pgp and BCRP inhibitor, could completely restore DOX sensitivity in MDCK-MDR1 cells. However, the cytotoxicity of DOX was not affected by the co-incubation of NOV at concentrations as high as $30 \mu \mathrm{M}$, indicating that NOV does not efficiently inhibit the efflux activity of Pgp. The inhibitory specificity of NOV was confirmed using fluorescent microcopy, which showed that GF120918 $(1 \mu \mathrm{M})$, but not NOV $(100 \mu \mathrm{M})$ markedly enhanced cellular accumulation of Rh123 $(10 \mu \mathrm{M})$ in MDCKMDR1 cells (Figure 3B). It is noteworthy that 1) the doubled exposure time was applied to detect Rh123 fluorescence in MDCK-MDR1 cells (with or without NOV). However, the fluorescence detected in MDCK-MDR1 cells (with or without NOV) was still significantly weaker than in MDCK-wt cells, and the signal strength was similar in MDCK-MDR1 cells with or without co-incubation of NOV, indicating that NOV did not inhibit efflux activity of Pgp. On the contrary, when 
GF120918 was included in the incubation mixture, Rh123 fluorescence detected in MDCK-MDR1 cells within half exposure time was slightly higher than in MDCK-wt cells suggesting that GF120918 is a effective Pgp inhibitor; 2) the inhibition of Pgp in MDCK-MDR1 cells by GF120918 resulted in a lower DOX $\mathrm{IC}_{50}$ value and higher Rh123 accumulation as compared to MDCK-wt cells. This is due to the endogenous canine Pgp expression in MDCK-wt cells [25] and complete inhibition of both transfected human Pgp and endogenous canine Pgp in MDCK-MDR1 cells by GF120918.

\section{Effect of NOV on pharmacokinetics of orally-dosed TPT in rats.}

In view of the potent and specific inhibition of BCRP-mediated efflux by NOV in vitro, the influence of NOV on TPT pharmacokinetics was investigated in vivo. As shown in Figure 4 and Table 1, coadministration of NOV (50 $\mathrm{mg} / \mathrm{kg})$ significantly increased the $\mathrm{AUC}_{0-720}, \mathrm{AUC}_{0-\infty}$ and $\mathrm{C}_{\max }$ of orally dosed TPT (2 $\mathrm{mg} / \mathrm{kg}$ ) by 3 , 3- and 4.5-fold, respectively.

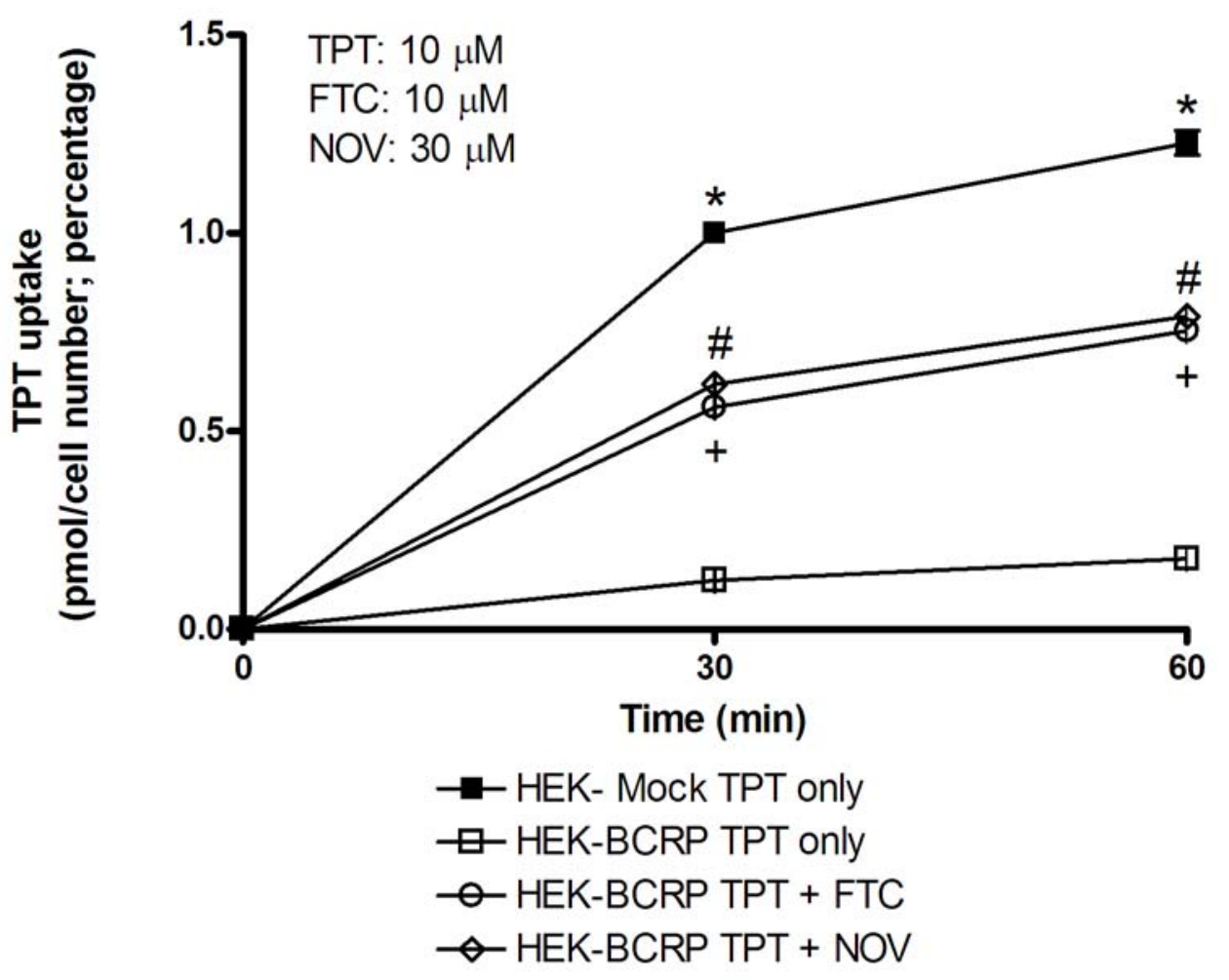

Figure 2. NOV significantly inhibits BCRP-mediated TPT efflux. HEK cells transfected with BCRP (HEKBCRP) or empty vector (HEK-Mock) were incubated with $10 \mu \mathrm{M}$ of TPT in the presence or absence of 30 $\mu \mathrm{M}$ of NOV or $10 \mu \mathrm{M}$ of FTC (a potent BCRP inhibitor as positive control). At the designated time point, the cellular accumulated TPT was quantitated by HPLC as described in Materials and methods, and then normalized to the cell number. Data was expressed as relevant value (TPT uptake in HEK-Mock cells at 30 min was set as one). Each point represents the mean \pm SD of three independent experiments. Comparison of TPT uptake (*: HEK-Mock vs. HEKC-BCRP; \#: HECK-BCRP vs. HEK-BCRP with NOV; +: HEK-BCRP vs. HECK-BCRP with FTC) at each time point showed statistical differences $(p<0.05)$. 
A

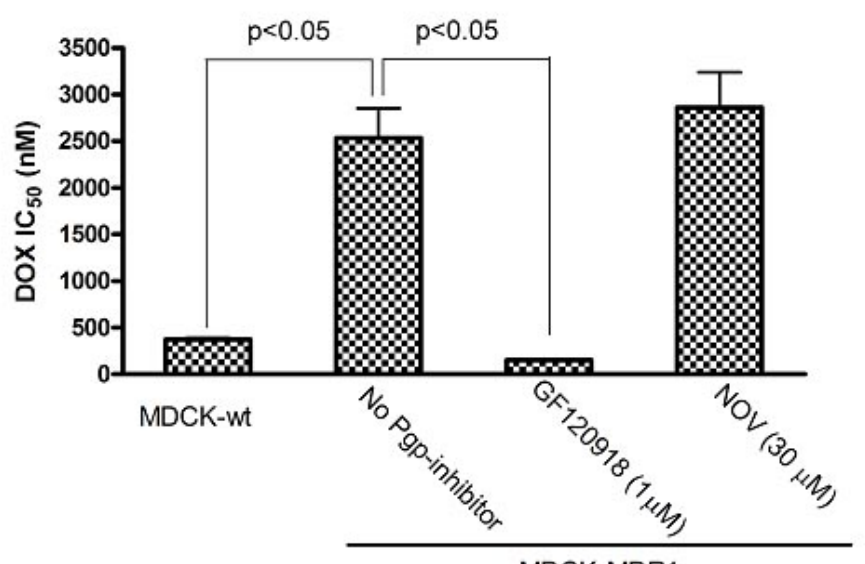

MDCK-MDR1

B

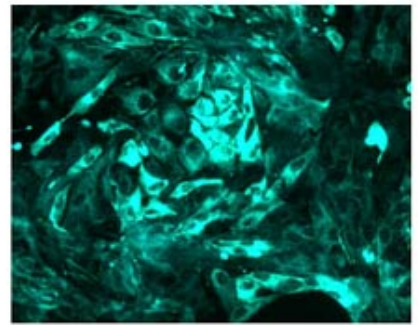

MDCK: Rh123

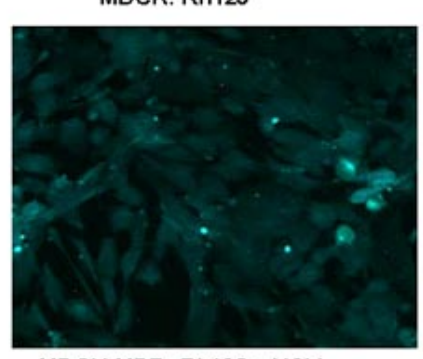

MDCK-MDR: Rh123 + NOV

$2 x$ exposure time

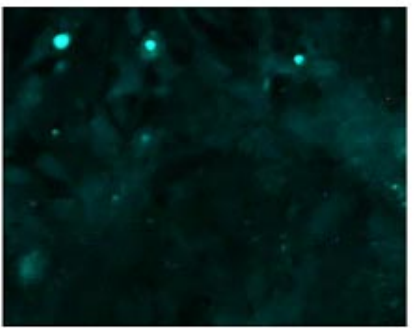

MDCK-MDR: Rh123

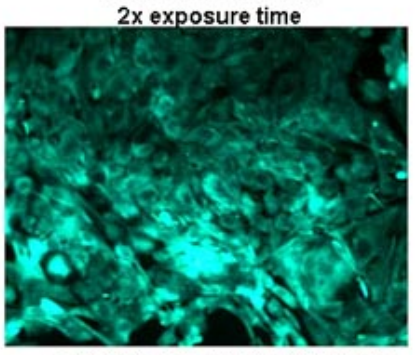

MDCK-MDR: Rh123 + GF120918

$1 / 2 x$ exposure time

Figure 3. NOV is not an inhibitor of Pgp. (A) The cytotoxicities of DOX (i.e., $\mathrm{IC}_{50}$ value of DOX) in the presence or absence of NOV $(30 \mu \mathrm{M})$ or GF120918 $(1 \mu \mathrm{M}$, a potent Pgp inhibitor as positive control) were measured by MTT assay as described in Materials and methods. Each bar represents mean \pm SD of four independent experiments. $p<0.05$ was regarded as statistically significant. (B) MDCK cells transfected with Pgp (MDCK-MDR1) or empty vector (MDCK-wt) were incubated with $10 \mu \mathrm{M}$ of Rh123 in the presence or absence of NOV $(100 \mu \mathrm{M})$ or GF120918 $(1 \mu \mathrm{M})$. Two hours later, the cellular accumulated Rh123 were assessed using fluorescence microscopy as described in Materials and methods. Note that double exposure time was used to capture the Rh123 florescence in MDCK-MDR1 or MDCK-MDR1 treated with NOV, while half exposure time for MDCK-MDR1 treated with GF120918. 


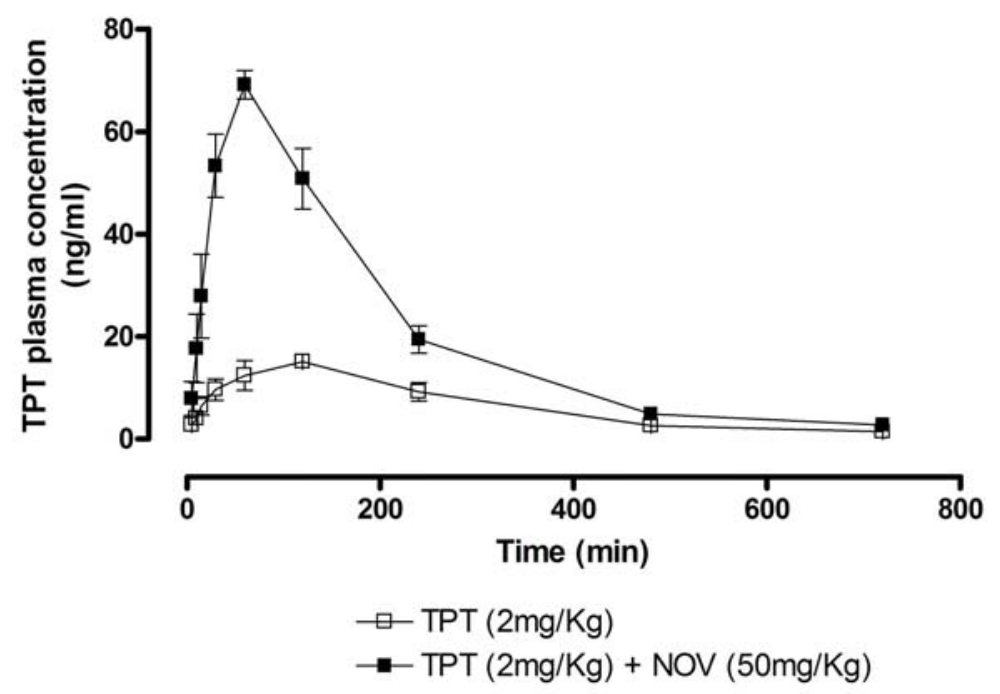

Figure 4. TPT rat total plasma concentration-time plots generated after a $2 \mathrm{mg} / \mathrm{kg}$ dose had been given orally with $(\square)$ or without $(\square)$ oral coadministration of NOV (50 mg/kg). Each data point represents mean \pm SD of three rats.

Table 1. Pharmacokinetic parameters of orally $(2 \mathrm{mg} / \mathrm{kg})$ or i.v. bolus $(1 \mathrm{mg} / \mathrm{kg})$ dosed TPT in SD rats with or without oral co-administration of NOV (50 mg/kg)

TPT (2 mg/kg) p.o.

TPT (1 mg/kg) i.v.

\begin{tabular}{|c|c|c|c|c|}
\hline & without NOV & with NOV & without NOV & with NOV \\
\hline $\mathrm{AUC}_{0-720}\left(\times 10^{3} \mathrm{ng} / \mathrm{ml} \cdot \mathrm{min}\right)$ & $4.66 \pm 0.36$ & $14.26 \pm 1.82 *$ & $21.99 \pm 4.25$ & $27.08 \pm 1.01 *$ \\
\hline $\mathrm{AUC}_{0-\infty}\left(\times 10^{3} \mathrm{ng} / \mathrm{ml} \cdot \mathrm{min}\right)$ & $5.02 \pm 0.30$ & $14.93 \pm 2.03 *$ & $22.96 \pm 4.08$ & $34.07 \pm 2.22 *$ \\
\hline $\mathrm{C}_{\max }(\mathrm{ng} / \mathrm{ml})$ & $15.49 \pm 2.21$ & $69.13 \pm 4.90 *$ & $\mathrm{n} / \mathrm{a}$ & $\mathrm{n} / \mathrm{a}$ \\
\hline $\mathrm{T}_{\max }(\min )$ & $100 \pm 34$ & $60 \pm 0 *$ & $\mathrm{n} / \mathrm{a}$ & $\mathrm{n} / \mathrm{a}$ \\
\hline $\mathrm{T}_{1 / 2}(\min )$ & $\mathrm{n} / \mathrm{a}$ & $\mathrm{n} / \mathrm{a}$ & $200 \pm 27$ & $881 \pm 356 *$ \\
\hline $\mathrm{MRT}_{\text {inf }}(\min )$ & $203 \pm 16$ & $274 \pm 17 *$ & $92 \pm 16$ & $509 \pm 236 *$ \\
\hline CL (ml/min/kg) & $\mathrm{n} / \mathrm{a}$ & $\mathrm{n} / \mathrm{a}$ & $44.40 \pm 7.28$ & $29.44 \pm 1.99 *$ \\
\hline Vdss $\left(\times 10^{3} \mathrm{ml} / \mathrm{kg}\right)$ & $\mathrm{n} / \mathrm{a}$ & $\mathrm{n} / \mathrm{a}$ & $4.15 \pm 1.28$ & $14.71 \pm 6.11 *$ \\
\hline
\end{tabular}

Orally administered NOV also significantly reduced the systemic clearance of TPT (Figure 5 and Table 1). The $\mathrm{AUC}_{0-480}$ and $\mathrm{AUC}_{0-\infty}$ of i.v. injected TPT increased from $21.99 \pm 4.25$ and $22.96 \pm 4.08\left(\times 10^{3}\right.$ $\mathrm{ng} / \mathrm{ml} \cdot \mathrm{min}$ ) without NOV to $27.08 \pm 1.01$ and $34.07 \pm 2.22\left(\times 10^{3} \mathrm{ng} / \mathrm{ml} \cdot \mathrm{min}\right)$, respectively, when NOV was co-administered $(p<0.05)$.
Accordingly, the systemic clearance of TPT significantly decreased from $44.40 \pm 7.28$ $\mathrm{ml} / \mathrm{min} / \mathrm{kg}$ without $\mathrm{NOV}$ to $29.44 \pm 1.99$ $\mathrm{ml} / \mathrm{min} / \mathrm{kg}$ with NOV $(p<0.05)$, while, the half life $\left(T_{1 / 2}\right)$ or mean residence time extrapolated to infinity ( $\mathrm{MRT}_{\text {inf }}$ ) were prolonged significantly. The increase of TPT volume of distribution at the steady state 
(Vdss) from $4.15 \pm 1.28$ to $14.71 \pm 6.11\left(\times 10^{3}\right.$ $\mathrm{ml} / \mathrm{kg}$ ) indicated that blocking of BCRPmediated efflux may lead the penetration and accumulation of TPT into some organs or tissues (e.g., brain) with BCRP-efflux as the barrier.

The plasma concentrations of NOV were simultaneously quantitated. As compared to $\mathrm{IC}_{50}$ value of NOV (i.e., $0.4 \mu \mathrm{M}$ ) obtained from the inhibition of BCRPmediated methotrexate efflux [26], NOV plasma concentrations within the entire time range for PK experiment of i.v. injected TPT (i.e., from 0 to $480 \mathrm{~min}$ ) were higher than 1 $\mu \mathrm{M}$ (Figure 5), and sufficient to inhibit in vivo BCRP activity.

\section{Assessment of the role of intestinal BCRP in TPT absorption using rat SPIP model with mesenteric vein sampling.}

To elucidate the role of intestinal Bcrp in the oral absorption of TPT, a rat single-perfuse intestinal perfusion model with mesenteric vein sampling was used. This method provides an isolated in vivo system, which allows for the direct and quantitative assessment of drug absorption and disposition in the intestine. The apparent mucosal to serosal permeability of TPT based on mesenteric vein blood appearance was estimated as $0.81 \pm 0.30 \times 10^{-6} \mathrm{~cm} / \mathrm{s}$. The inclusion of NOV $(500 \mu \mathrm{M})$ in the intestinal perfusate significantly increased TPT permeability to $1.26 \pm 0.12 \times 10^{-6} \mathrm{~cm} / \mathrm{s}$ (Figure 6), indicating that intestinal Bcrp plays an important role in limiting TPT brush border membrane permeation from the lumen to blood, which subsequently lowers its oral bioavailability.

\section{Assessment of the role of Bcrp in TPT exsorption across rat ileum in situ.}

Bcrp, as an efflux transporter in the intestine, not only restricts drug absorption from the lumen to the blood, but it also actively secretes drug from the systemic blood circulation into the intestinal lumen - a process also known as “exsorption”. In order to test whether TPT undergoes Bcrp-mediated exsorption, the appearance of TPT was measured in the intestinal segment following i.v. infusion. The role of Bcrp in TPT exsorption was also assessed by including NOV $(500 \mu \mathrm{M})$ in the intestinal perfusate to inhibit brush border membrane-localized Bcrp function. As shown in Figure 7A, the intestinal clearance of TPT in a 15-cm long ileal segment decreased significantly when Bcrp was inhibited (i.e., rat-4, -5 and -6). Since this perfusion study had a relatively long time frame, which might result in the loss of integrity of intestinal tissues and mesenteric blood circulation in the late stages of perfusion, a sham inhibition group (i.e., perfusion with continuous saline instead of saline containing $\mathrm{NOV}$ at 90-min) was included to rule out the influence of perfusion time. As shown in Figure 7A, TPT clearance during sham inhibition was not significantly reduced (i.e., rat-1, -2 and -3), as compared to their respective control phase. The change of mean value of TPT clearance across the phase (from control to Bcrp inhibition, or from control to sham inhibition) was then compared between Bcp inhibition and sham inhibition groups using Repeated-Measures Analysis (Figure 7B). Based on this analysis, it is concluded that inhibition of intestinal Bcrp significantly decreased TPT exsorption.

\section{DISCUSSION}

The current study clearly demonstrated that NOV inhibits only BCRP and not Pgp activity. By using NOV as potent and specific BCRP inhibitor, we mechanistically assessed the role of intestinal BCRP in the absorption and disposition of TPT in situ and in vivo. In vivo pharmacokinetic studies in rats demonstrated that coadministration of NOV significantly increased oral TPT bioavailability by enhancing intestinal absorption and decreasing systemic clearance. 


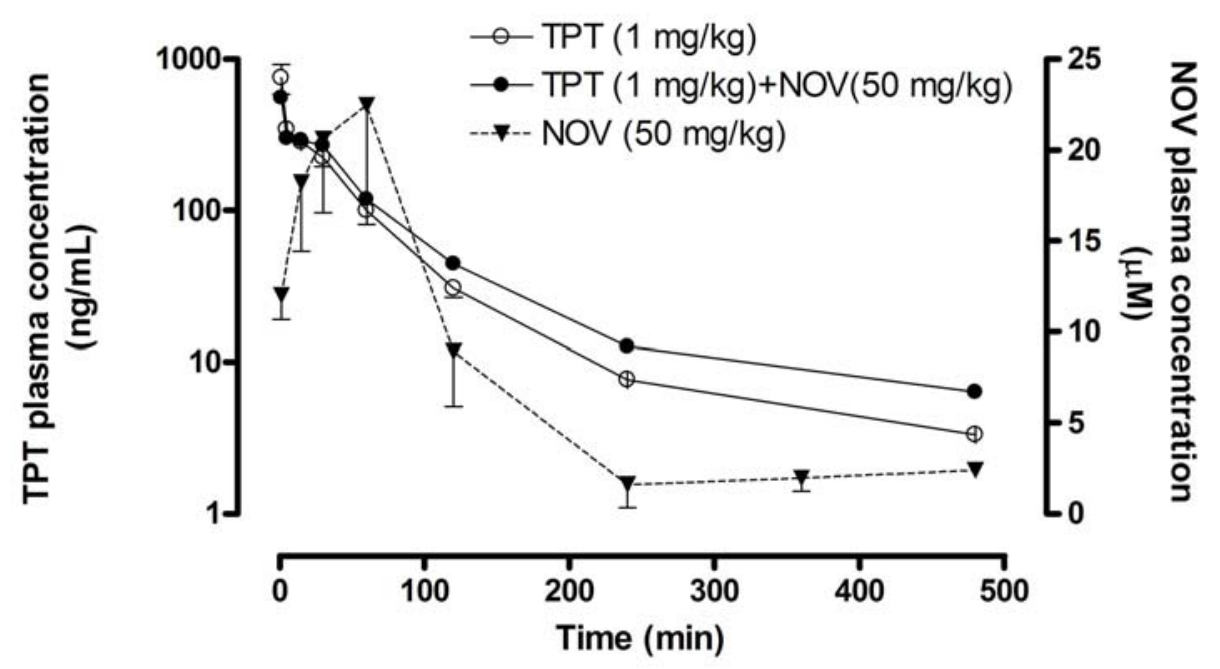

Figure 5. TPT rat total plasma concentration-time plots generated after a $1 \mathrm{mg} / \mathrm{kg}$ dose had been given i.v. with $(\bullet)$ or without $(O)$ oral coadministration of NOV $(50 \mathrm{mg} / \mathrm{kg})$. NOV plasma concentration $(\boldsymbol{\nabla})$ was quantitated simultaneously and plotted together with TPT data. Each data point represents mean \pm SD of three rats.

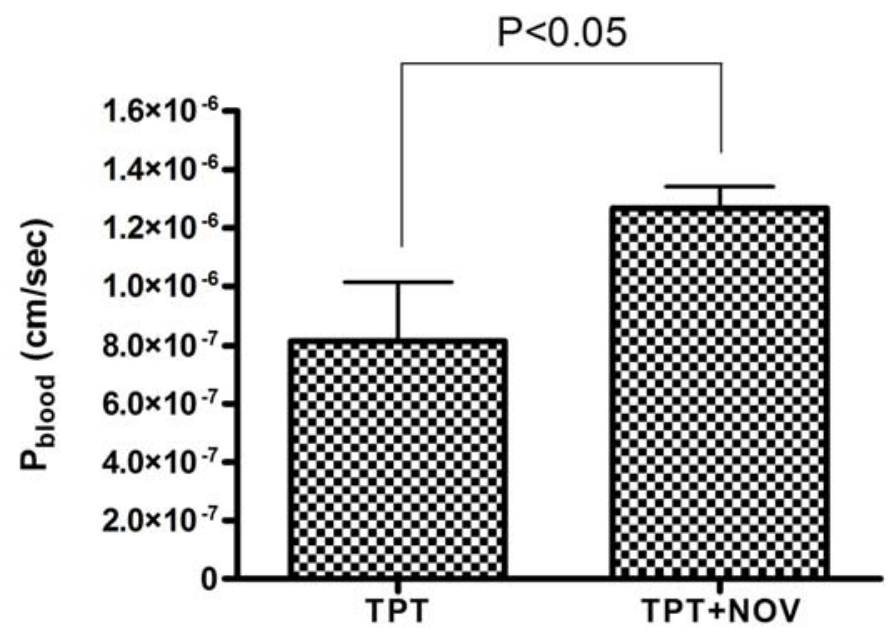

Figure 6. Apparent permeability of TPT $(10 \mu \mathrm{M})$ across rat ileum alone or in the presence of NOV $(500 \mu \mathrm{M})$. Data shown are mean \pm SD $(n=3)$. $p$ value $<0.05$ is regarded as statistically significant. 
A

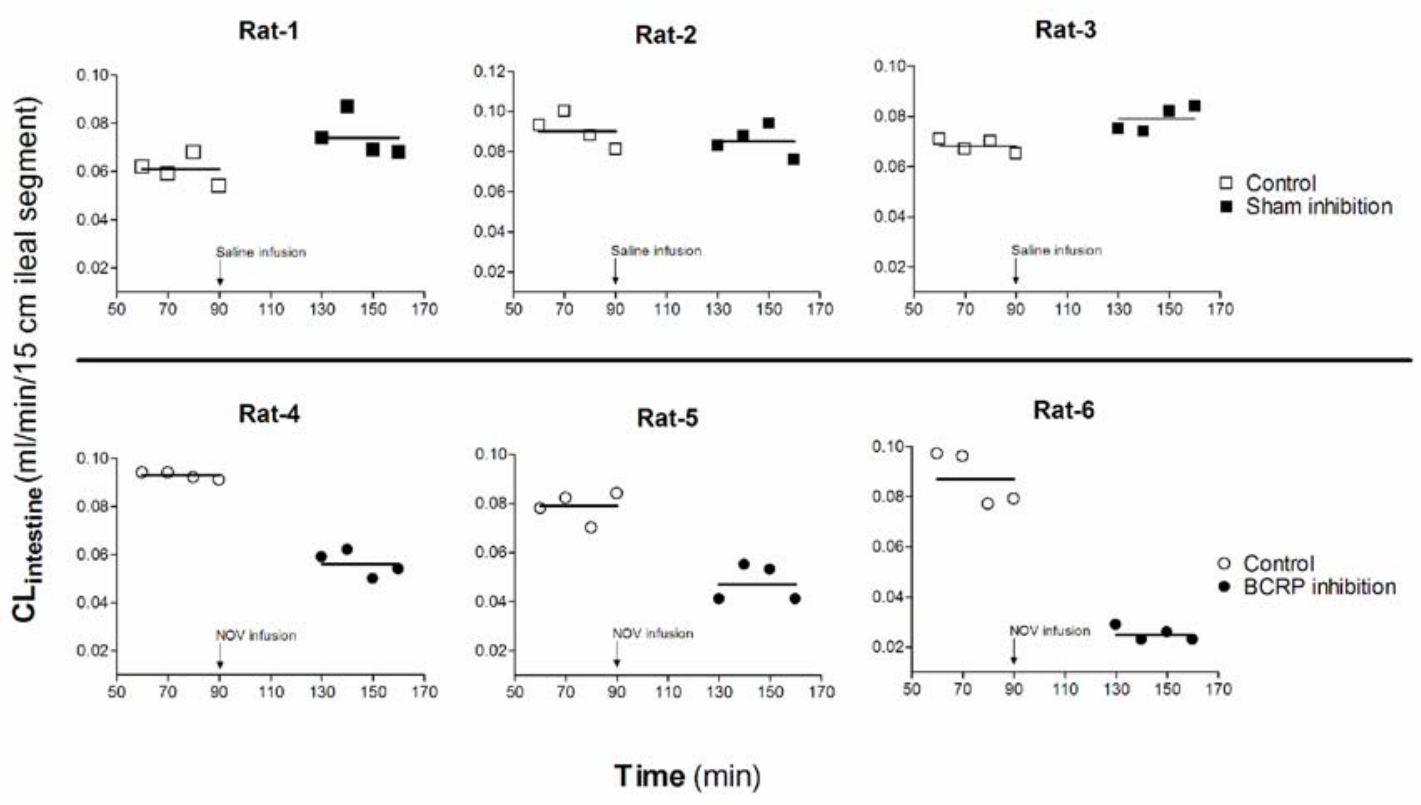

B

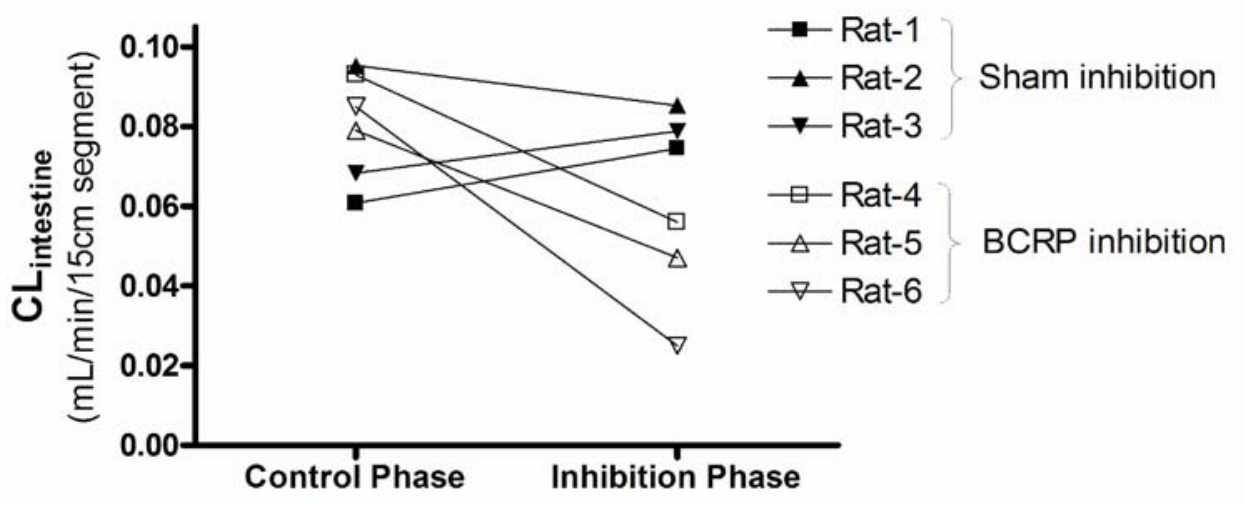

Figure 7. (A) The effect of Bcrp inhibition on intestinal secretion (exsorption from blood to intestinal lumen) of TPT. As described in Materials and methods, rat ileal segment was perfused with normal saline in the absence $(\bigcirc$, control phase) or presence $(\bullet$, Bcrp inhibition phase) of $500 \mu \mathrm{M}$ luminal NOV when TPT plasma concentration is at the steady-state (approximately $100 \mathrm{ng} / \mathrm{ml}$ ). To rule out the long experimental time frame-introduced influence on TPT exsorption, rat ileal segment was continuously perfused with normal saline within the entire experimental duration ( $\square$, control phase; $\mathbf{\square}$, sham inhibition phase). TPT exsorption (i.e., $\mathrm{CL}(\mathrm{ml} / \mathrm{min} / 15 \mathrm{~cm}$ ileal segment)) was calculated as described in Materials and methods. The solid line represents the mean of TPT clearance in each phase. Arrows denote the initiation of NOV or continuous saline perfusion into the ileal lumen. (B) The change of average intestinal TPT clearance from the control to inhibition phase was compared across the different treatment groups (i.e., sham or Bcrp inhibition) using Repeated-Measures Analysis. As compared to sham inhibition group (rat-1, -2 and -3), Bcrp inhibition (rat-4, -5 , and -6$)$ significantly reduced TPT exsorption $(p<0.05)$. 
Moreover, the results from in situ intestinal perfusions provide direct evidence that intestinal BCRP plays an important role in limiting TPT oral absorption as well as mediating TPT elimination after i.v. infusion. This highlights the relative importance of direct intestinal TPT secretion (i.e., from enterocytes) as compared to biliary secretion (i.e., from hepatocytes then into the bile duct). Assuming that small intestinal secretion of TPT is consistent across the different regions (i.e., duodenum, jejunum and ileum), its clearance by entire small intestine (length of $120 \mathrm{~cm}$ as suggested by by Kararli) [27] can be scaled up from the measured $\mathrm{CL}_{\text {intestine }}$ in ileal segment $(0.080 \pm$ $0.013 \mathrm{~mL} / \mathrm{min} / 15 \mathrm{~cm}$ segment), which is obtained by averaging control phase $\mathrm{CL}_{\text {intestine }}$ from rat 1 to 6 with body weight of $250 \mathrm{~g}$. Thus, it is estimated that TPT clearance by small intestine $(2.56 \pm 0.42 \mathrm{~mL} / \mathrm{min} / \mathrm{kg})$ is approximately $6 \%$ of total clearance $(44.40 \pm$ $7.28 \mathrm{~mL} / \mathrm{min} / \mathrm{kg}$ ).

Permeability, a parameter obtained in biopharmaceutical study, estimates the drug transport rate across the biological membrane. In the current study, the apparent permeability (i.e., TPT transport from intestinal mucosal to serosal side) was measured based on the appearance of TPT in the mesenteric blood. Mechanistically, the apparent (i.e., total or effective) membrane permeability is the sum of the individual components that occur in parallel including passive diffusion and carrier-mediated absorptive (i.e., from intestinal mucosal to serosal side) or secretive transport (i.e., from serosal to mucosal side). [1] One may argue that intestinal Bcrp may not be a major contributor to its low oral bioavailability since TPT permeability increased only $\sim 1.5$ fold when NOV was included in the perfusate. However, in the current in situ study, the steady state apparent permeability of TPT was measured (i.e., intestinal drug concentration is constant at $10 \mu \mathrm{M}$ in the perfusate). It has been demonstrated that apparent permeability is a concentrationdependent parameter when carrier-mediated transport is involved [28]. Since local intestinal drug concentrations change dynamically after oral administration, unlike concentrations in the steady-state permeability approach, the correlation between approaches is difficult to assess. TPT undergoes minimal metabolism in rats and humans [29, 30], therefore, the drug-drug interaction between TPT and NOV is presumably mediated by transporters. While the importance of intestinal Bcrp on TPT oral bioavailability was demonstrated in the current study, the contribution of biliary secretion should not be underestimated. In other words, orally coadministered NOV can inhibit Bcrp at the hepatic canalicular membrane, consequently reducing the biliary secretion of TPT and enhancing its oral bioavailability.

One concern of using efflux transporter inhibitors to enhance drug exposure in patients is the increased risk of challenges by harmful endogenous or exogenous substances, which are normally effluxed out of the human body by functional secretory transporters in organs or tissues with barrier functions. Therefore, the ideal transporter inhibitor is one that would be specific with a defined and short half-life of action. In this way, the efflux-associated detoxification system would not be severely comprised. The present in vitro and in vivo findings that NOV significantly inhibits BCRP-mediated substrate drug efflux may favorably accelerate the clinical implementation of NOV as a BCRP inhibitor due to the following unique properties of NOV: i) unlike other BCRP inhibitors such as GF120918 or FTC, NOV has been clinically used for decades as a well-tolerable and safe drug, ii) the maximal-tolerated dose in humans is as high as 4 gram per day [31]; and iii) NOV inhibits only BCRP and not Pgp, thereby reducing the incidence of unwanted drug-drug interactions and lowering the risk of exposure to other harmful substance. The recent study demonstrated that some excipients (e.g., pluronic P85 and Tween 20) significantly increased the 
intestinal absorption rate of TPT by inhibiting BCRP [32]. It would be interesting to know whether NOV and these excipients have the similar inhibitory mechanism.

It has been found that cancer cells, which are initially sensitive to chemotherapy, become resistant to a wide spectrum of structurally and functionally distinct drugs after a single drug treatment over a certain period of time - a phenomenon known as multidrug resistance (MDR) [33]. One of the intensively-studied mediators of MDR is the upregulation of ABC transporters (e.g., BCRP), which results in low intracellular drug concentration in cancer cells [34]. The current study suggested that NOV can be used to block BCRP-mediated drug efflux, potentially reversing MDR. Future study is warranted to test this hypothesis.

In summary, the present study demonstrated that NOV is a potent and specific BCRP inhibitor at both in vitro and in vivo. The data from in situ perfusion work provide direct evidence that intestinal Bcrp plays an important role in limiting the oral absorption of TPT and substantially mediates TPT elimination after i.v. infusion.

\section{ACKNOWLEDGMENTS}

This work was supported by the Parke-Davis Endowed Chair. We thank Dr. Xiaoping Zhang for his technical assistance in microscopy. We also thank Dr. Eric Rubin (CINJ) and Dr. Susan Bates (NCI) for providing us with cell lines used in this study.

\section{REFERENCES:}

[1]. Kunta JR and Sinko PJ. Intestinal drug transporters: in vivo function and clinical importance. Curr Drug Metab, 5:109124, 2004.

[2]. Chu XY, Sanchez-Castano GP, Higaki K, Oh DM, Hsu CP, and Amidon GL. Correlation between epithelial cell permeability of cephalexin and expression of intestinal oligopeptide transporter. J Pharmacol Exp Ther, 299:575-582, 2001.
[3]. Sinko PJ, Kunta JR, Usansky HH, and Perry BA. Differentiation of gut and hepatic first pass metabolism and secretion of saquinavir in ported rabbits. J Pharmacol Exp Ther, 310:359-366, 2004.

[4]. Miyake K, Mickley L, Litman T, Zhan Z, Robey R, Cristensen B, Brangi M, Greenberger L, Dean M, Fojo T, and Bates SE. Molecular Cloning of cDNAs Which Are Highly Overexpressed in Mitoxantrone-resistant Cells: Demonstration of Homology to ABC Transport Genes. Cancer Res, 59:8-13, 1999.

[5]. Doyle LA, Yang W, Abruzzo LV, Krogmann T, Gao Y, Rishi AK, and Ross DD. A multidrug resistance transporter from human MCF-7 breast cancer cells. Proc Natl Acad Sci U S A, 95:1566515670, 1998.

[6]. Maliepaard M, Scheffer GL, Faneyte IF, van Gastelen MA, Pijnenborg AC, Schinkel AH, van de Vijver MJ, Scheper RJ, and Schellens JH. Subcellular localization and distribution of the breast cancer resistance protein transporter in normal human tissues. Cancer Res, 61:3458-3464, 2001.

[7]. Creemers GJ, Gerrits CJ, Eckardt JR, Schellens JH, Burris HA, Planting AS, Rodriguez GI, Loos WJ, Hudson I, Broom C, Verweij J, and Von Hoff DD. Phase I and pharmacologic study of oral topotecan administered twice daily for 21 days to adult patients with solid tumors. J Clin Oncol, 15:1087-1093, 1997.

[8]. De Cesare M, Zunino F, Pace S, Pisano C, and Pratesi G. Efficacy and toxicity profile of oral topotecan in a panel of human tumour xenografts. Eur J Cancer, 36:1558-1564, 2000.

[9]. Leger F, Loos WJ, Fourcade J, Bugat R, Goffinet M, Mathijssen RH, Verweij J, Sparreboom A, and Chatelut E. Factors affecting pharmacokinetic variability of oral topotecan: a population analysis. $\mathrm{Br}$ J Cancer, 90:343-347, 2004.

[10]. Jonker JW, Buitelaar M, Wagenaar E, Van Der Valk MA, Scheffer GL, Scheper RJ, Plosch T, Kuipers F, Elferink RP, Rosing H, Beijnen JH, and Schinkel AH. The breast cancer resistance protein protects against a major chlorophyll- 
derived dietary phototoxin and protoporphyria. Proc Natl Acad Sci U S A, 99:15649-15654, 2002.

[11]. Jonker JW, Smit JW, Brinkhuis RF, Maliepaard M, Beijnen JH, Schellens JH, and Schinkel AH. Role of breast cancer resistance protein in the bioavailability and fetal penetration of topotecan. J Natl Cancer Inst, 92:1651-1656, 2000.

[12]. Kruijtzer CM, Beijnen JH, Rosing H, Bokkel Huinink WW, Schot M, Jewell RC, Paul EM, and Schellens JH. Increased oral bioavailability of topotecan in combination with the breast cancer resistance protein and $\mathrm{P}$ glycoprotein inhibitor GF120918. J Clin Oncol, 20:2943-2950, 2002.

[13]. Allen JD, van Loevezijn A, Lakhai JM, van $d V$, van Tellingen $O$, Reid $G$, Schellens JH, Koomen GJ, and Schinkel $\mathrm{AH}$. Potent and specific inhibition of the breast cancer resistance protein multidrug transporter in vitro and in mouse intestine by a novel analogue of fumitremorgin C. Mol Cancer Ther, 1:417-425, 2002.

[14]. Rabindran SK, Ross DD, Doyle LA, Yang W, and Greenberger LM. Fumitremorgin $\mathrm{C}$ reverses multidrug resistance in cells transfected with the breast cancer resistance protein. Cancer Res, 60:47-50, 2000.

[15]. Zhang S, Wang X, Sagawa K, and Morris ME. Flavonoids chrysin and benzoflavone, potent breast cancer resistance protein inhibitors, have no significant effect on topotecan pharmacokinetics in rats or mdr1a/1b (-/) mice. Drug Metab Dispos, 33:341-348, 2005.

[16]. Gupta A, Zhang Y, Unadkat JD, and Mao Q. HIV protease inhibitors are inhibitors but not substrates of the human breast cancer resistance protein (BCRP/ABCG2). J Pharmacol Exp Ther, 310:334-341, 2004.

[17]. Shiozawa K, Oka M, Soda H, Yoshikawa M, Ikegami Y, Tsurutani J, Nakatomi K, Nakamura Y, Doi S, Kitazaki T, Mizuta Y, Murase K, Yoshida H, Ross DD, and Kohno S. Reversal of breast cancer resistance protein (BCRP/ABCG2)mediated drug resistance by novobiocin, a coumermycin antibiotic. Int J Cancer, 108:146-151, 2004.
[18]. Yang CH, Chen YC, and Kuo ML. Novobiocin sensitizes BCRP/MXR/ABCP overexpressing topotecan-resistant human breast carcinoma cells to topotecan and mitoxantrone. Anticancer Res, 23:25192523, 2003.

[19]. Robey RW, Honjo Y, Morisaki K, Nadjem TA, Runge S, Risbood M, Poruchynsky MS, and Bates SE. Mutations at amino-acid 482 in the ABCG2 gene affect substrate and antagonist specificity. $\mathrm{Br} \mathrm{J}$ Cancer, 89:1971-1978, 2003.

[20]. Su Y, Lee SH, and Sinko PJ. Inhibition of efflux transporter ABCG2/BCRP does not restore mitoxantrone sensitivity in irinotecan-selected human leukemia CPT-K5 cells: Evidence for multifactorial multidrug resistance. Eur J Pharm Sci, 29:102-110, 2006.

[21]. Singhal D, Ho NF, and Anderson BD. Absorption and intestinal metabolism of purine dideoxynucleosides and an adenosine deaminase-activated prodrug of 2',3'-dideoxyinosine in the mesenteric vein cannulated rat ileum. J Pharm Sci, 87:569-577, 1998.

[22]. Yumoto R, Murakami T, Nakamoto Y, Hasegawa R, Nagai J, and Takano M. Transport of rhodamine 123, a Pglycoprotein substrate, across rat intestine and Caco- 2 cell monolayers in the presence of cytochrome P-450 3Arelated compounds. J Pharmacol Exp Ther, 289:149-155, 1999.

[23]. Maliepaard M, van Gastelen MA, Tohgo A, Hausheer FH, van Waardenburg RC, de Jong LA, Pluim D, Beijnen JH, and Schellens JH. Circumvention of breast cancer resistance protein (BCRP)mediated resistance to camptothecins in vitro using non-substrate drugs or the BCRP inhibitor GF120918. Clin Cancer Res, 7:935-941, 2001.

[24]. Gupta A, Dai Y, Vethanayagam RR, Hebert MF, Thummel KE, Unadkat JD, Ross DD, and Mao Q. Cyclosporin A, tacrolimus and sirolimus are potent inhibitors of the human breast cancer resistance protein (ABCG2) and reverse resistance to mitoxantrone and topotecan. Cancer Chemother Pharmacol, 58:374383, 2006. 
[25]. Tang F, Horie K, and Borchardt RT. Are MDCK cells transfected with the human MDR1 gene a good model of the human intestinal mucosa? Pharm Res, 19:765772, 2002.

[26]. Saito H, Hirano H, Nakagawa H, Fukami T, Oosumi K, Murakami K, Kimura H, Kouchi T, Konomi M, Tao E, Tsujikawa N, Tarui S, Nagakura M, Osumi M, and Ishikawa T. A New Strategy of HighSpeed Screening and Quantitative SAR Analysis To Evaluate Human ABC Transporter ABCG2-Drug Interactions. J Pharmacol Exp Ther, 2006.

[27]. Kararli TT. Comparison of the gastrointestinal anatomy, physiology, and biochemistry of humans and commonly used laboratory animals. Biopharm Drug Dispos, 16:351-380, 1995.

[28]. Kunta J, Yan J, Makhey VD, and Sinko PJ. Active efflux kinetics of etoposide from rabbit small intestine and colon. Biopharm Drug Dispos, 21:83-93, 2000.

[29]. Rosing H, Herben VM, van Gortel-van Zomeren DM, Hop E, Kettenes-van den Bosch JJ, ten Bokkel Huinink WW, and Beijnen JH. Isolation and structural confirmation of N-desmethyl topotecan, a metabolite of topotecan. Cancer Chemother Pharmacol, 39:498-504, 1997.
[30]. Platzer P, Schaden S, Thalhammer T, Hamilton G, Rosenberg B, Silgoner I, and Jager W. Biotransformation of topotecan in the isolated perfused rat liver: identification of three novel metabolites. Anticancer Res, 18:26952700, 1998.

[31]. Kennedy MJ, Armstrong DK, Huelskamp AM, Ohly K, Clarke BV, Colvin OM, Grochow LB, Chen TL, and Davidson NE. Phase I and pharmacologic study of the alkylating agent modulator novobiocin in combination with highdose chemotherapy for the treatment of metastatic breast cancer. J Clin Oncol, 13:1136-1143, 1995.

[32]. Yamagata T, Kusuhara H, Morishita M, Takayama K, Benameur $\mathrm{H}$, and Sugiyama Y. Improvement of the oral drug absorption of topotecan through the inhibition of intestinal xenobiotic efflux transporter, breast cancer resistance protein, by excipients. Drug Metab Dispos, 35:1142-1148, 2007.

[33]. Michor F, Nowak MA, and Iwasa Y. Evolution of resistance to cancer therapy. Curr Pharm Des, 12:261-271, 2006.

[34]. Polgar O and Bates SE. ABC transporters in the balance: is there a role in multidrug resistance? Biochem Soc Trans, 33:241245, 2005. 